\title{
Knowledge and Self-Care Practice Regarding Diabetes among Patient Diagnosed with Diabetes Mellitus in Selected Hospitals, Kamrup (M), Assam, with a View to Develop Information Booklet on Management of Diabetes: A Descriptive Study
}

\author{
Shelly Chabungbam ${ }^{1}$, Sabita Bayan ${ }^{2}$ \\ ${ }^{1}$ MSc. Nursing, Department of Medical Surgical Nursing, Asian Institute of Nursing Education, Guwahati, \\ Assam, India \\ ${ }^{2}$ Associate Professor, Department of Psychiatric Nursing, Asian Institute of Nursing Education Guwahati, \\ Assam, India \\ Corresponding Author: Shelly Chabungbam
}

\begin{abstract}
Background: Diabetes is a group of metabolic diseases characterized by high blood glucose level resulting from defects in insulin secretion, insulin action, or both. The chronic long term hyperglycemia of diabetes is associated with long-term damage, dysfunction, and failure of different organs, especially the eyes, kidneys, nerves, heart, and blood vessels.

Aim and Objective: To assess the knowledge and self-care practice regarding diabetes among patient diagnosed with diabetes mellitus in selected hospitals Kamrup (M), Assam

Methods and materials: A descriptive survey design was used to accomplish the objectives. 100 diabetic patients were selected as sample by using purposive sampling technique. Structured knowledge questionnaire and inventory checklist were used to assess the level of knowledge and selfcare practice.

Results: The study revealed that out of 100 sample, majority 84(84\%) had moderate knowledge, and majority $52(52 \%)$ had adequate practice regarding management of diabetes. There was moderate positive correlation between knowledge and practice score as the calculated $r$ value is 0.43 .There was significant association between the level of knowledge and practice with the demographic variables such as educational status, occupation, place of residence and duration of diabetes. There was also significant association between the level of practice with the demographic variables such as availability of glucometer a home, attended session of health education on diabetes and current treatment for diabetes.
\end{abstract}

Conclusion: Hence, proper awareness regarding self-care management of diabetes is needed in order to improve the knowledge and self-care practice among diabetic patient.

Keywords: knowledge, self-care practice, Diabetes mellitus, Information booklet

INTRODUCTION

According to World health organization report (2019), diabetes is the direct cause of 1.5 million deaths. Between 2000 and 2016, there was an increased in premature mortality by $5 \%$. In high-income countries the premature mortality rate due to diabetes decreased from 2000 to 2010 but then the mortality rate was increased again in 2010-2016. In lower-middle-income countries, the premature mortality rate due to diabetes is increasing.

According to the International Diabetes Foundation report, it is being said 
Shelly Chabungbam et.al. Knowledge and self-care practice regarding diabetes among patient diagnosed with diabetes mellitus in selected hospitals, Kamrup (M), Assam, with a view to develop information booklet on management of diabetes: a descriptive study.

that India had more cases of diabetes than any other country in the world. Diabetes mellitus is affecting more than 62 million Indians, Nearly 1 million Indians die due to diabetes every year. According to the Indian Heart Association suggests that India is projected to be home to 109 million individuals with diabetes by the year 2035.A study by the American Diabetes Association suggests that India will see the greatest increase in the number of people diagnosed with diabetes mellitus by the year 2030.

Since diabetes is a chronic disease requiring a multi-prolonged approach for its management, where in the patient has important role to play. Patient with diabetes need to follow certain self -care practices to achieve an optimal glycemic control and prevent complications

These self-care practices include regular physical activity, appropriate dietary management, stress management, mouth care, daily foot care practice, compliance with treatment regimen and tackling complications such as hypoglycemic episodes. Thus the objective of the study was to assess the baseline knowledge and self- care practice regarding diabetes among patient diagnosed with diabetes mellitus so that in future it will serve as a bench mark for future comparisons to assess the effectives of any educational training program for the diabetic patients. ${ }^{[2]}$

\section{PROBLEM STATEMENT}

"Knowledge and self-care practice regarding Diabetes among patient diagnosed with Diabetes Mellitus in selected hospitals, Kamrup (M), Assam, with a view to develop Information booklet on Management of Diabetes: A Descriptive study

\section{OBJECTIVES}

1. To assess the knowledge and self-care practice regarding Diabetes among patient admitted in selected hospitals of Kamrup (M), Assam.

2. To co-relate the knowledge and self-care practice regarding Diabetes.
3. To find out the association between knowledge and self-care practice with the selected demographic variables.

4. To develop an information booklet on Management of Diabetes.

\section{METHODS}

Descriptive survey research design was used to conduct the study among the selected hospitals of Kamrup (M), Assam. A total of 100 diabetic patients were selected by using purposive sampling technique. The samples included in the study were who fulfilled the inclusion and exclusion criteria. Ethical permission was obtained prior to data collection. After collecting formal permission from the HR department of Hayat hospital and health city hospital, Guwahati, Assam. The investigator approached the respondents who have fulfilled the inclusion criteria. Consent has been taken and only those who participated are included in the study. The structured tools for assessing the knowledge and selfcare practice were administered and the approximate time taken by each sample was 30 to 45 minutes. The investigator collected back the tool and information booklet regarding management of diabetes was provided to each respondent. The collected data were analyzed in terms of the objectives of the study by using descriptive and inferential statistics.

\section{DESCRIPTION OF THE TOOL}

The structured tool used for this study consists of three sections:

Section I: Demographic data. It consists of age, sex, Marital status, Religion, Educational status, Occupation, BMI, Place of residence, Type of Diabetes, Duration of Diabetes, Family history of Diabetes, any other illness suffering from, Availability of Glucometer at home, Attended session of health education on Diabetes and current treatment for Diabetes.

Section II: Structured knowledge questionnaire. It consists of 24 questions related to knowledge about diabetes, types of Diabetes, Risk Factors, diagnosis, 
Shelly Chabungbam et.al. Knowledge and self-care practice regarding diabetes among patient diagnosed with diabetes mellitus in selected hospitals, Kamrup (M), Assam, with a view to develop information booklet on management of diabetes: a descriptive study.

complication, prevention and management of diabetes.

Section III: Inventory checklist. It consists of 14 items related to domains of self- care practice which includes foot care, diet, exercise, regular monitoring of blood glucose level and regular follow up.

\section{RESULTS}

\section{Section - 1: Description of demographic variables}

Table 1: Frequency and percentage distribution of demographic variables of patients with diabetes mellitus.

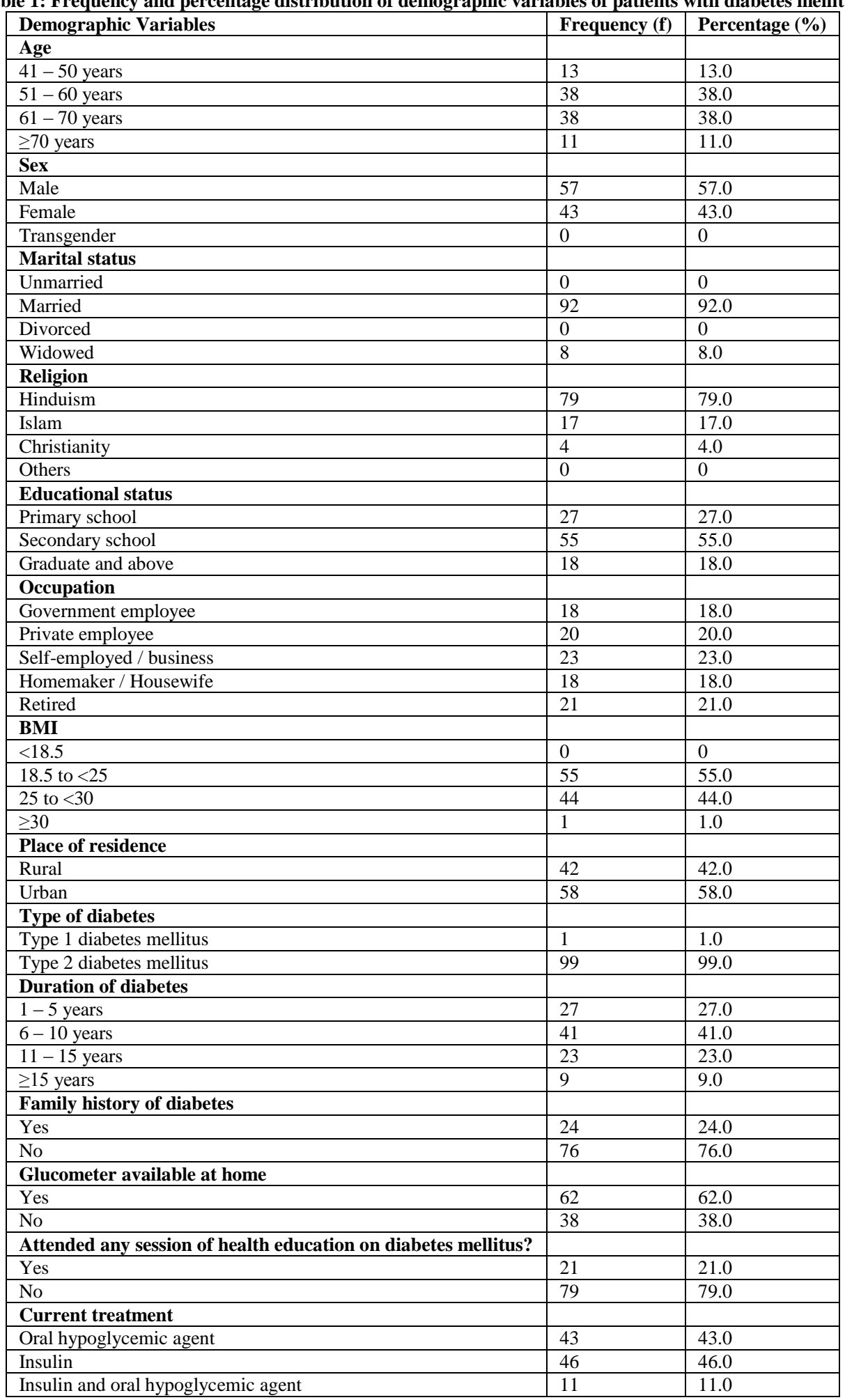


Shelly Chabungbam et.al. Knowledge and self-care practice regarding diabetes among patient diagnosed with diabetes mellitus in selected hospitals, Kamrup (M), Assam, with a view to develop information booklet on management of diabetes: a descriptive study.

SECTION-II Assessment of the

knowledge and practice scores of the

patient regarding management of

Diabetes.

Table 2: Frequency and percentage distribution of the level of knowledge regarding diabetes among patient diagnosed with diabetes mellitus

\begin{tabular}{|l|l|l|}
\hline Level of Knowledge & $\begin{array}{l}\text { Frequency } \\
\text { (f) }\end{array}$ & $\begin{array}{l}\text { Percentage } \\
(\%)\end{array}$ \\
\hline Inadequate Knowledge $(<8)$ & 12 & 12.0 \\
\hline Moderate Knowledge $(8-16)$ & 84 & 84.0 \\
\hline Adequate Knowledge $(>16)$ & 4 & 4.0 \\
\hline
\end{tabular}

The table 2 reveals that majority $84(84 \%)$ had moderate knowledge, 12(12\%) had inadequate knowledge and only four
(4\%) had adequate knowledge regarding diabetes among patients diagnosed with diabetes mellitus.

Table 3: Frequency and percentage distribution of the level of
practice among patients diagnosed with diabetes mellitus
\begin{tabular}{|l|l|l|}
\hline Level of Practice & Frequency (f) & Percentage $(\%)$ \\
\hline Inadequate Practice $(<5)$ & 0 & 0 \\
\hline Moderate Practice $(5-9)$ & 48 & 48.0 \\
\hline Adequate Practice $(>9)$ & 52 & 52.0 \\
\hline
\end{tabular}

The table 3 reveals that majority $52(52 \%)$ had adequate practice and 48(48\%) had moderate practice regarding diabetes among patients diagnosed with diabetes mellitus.

\section{Section III: Correlation between knowledge and self-care practice regarding management of diabetes}

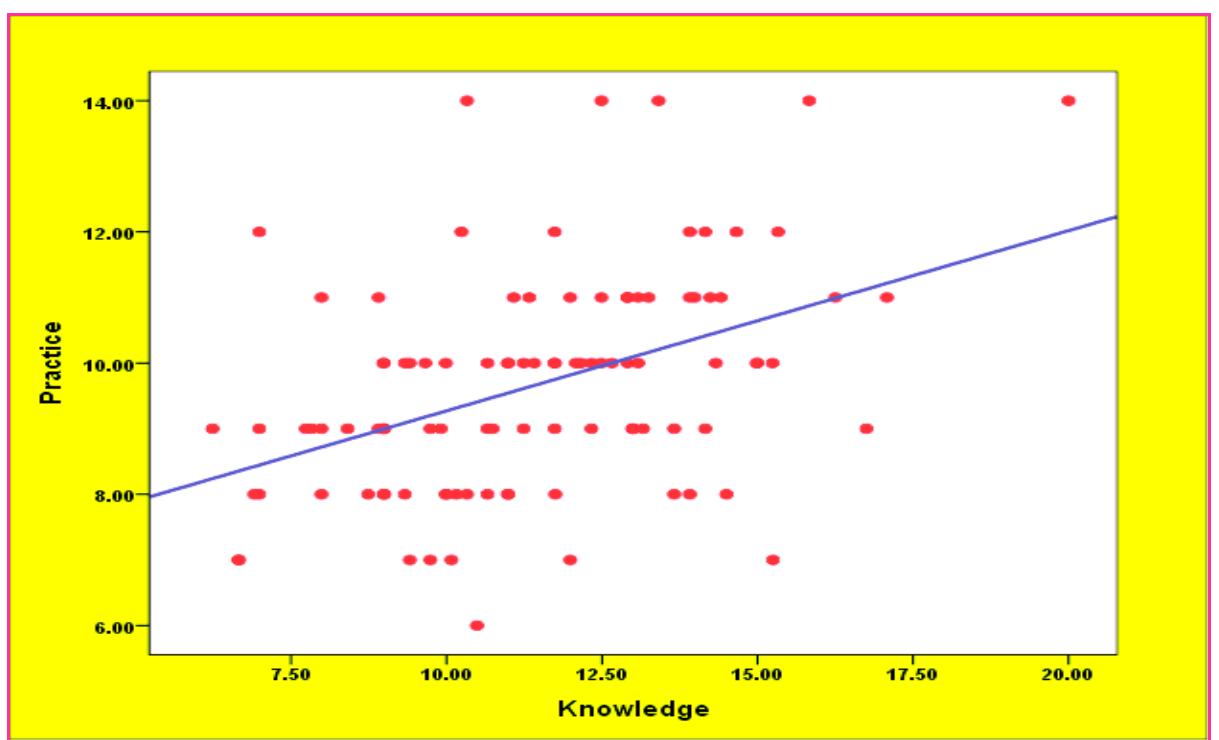

Figure 1 : Scatter dot diagram showing the correlation between knowledge and practice scores regarding diabetes among patients diagnosed with diabetes mellitus $(r=0.430)$.

The table depicts that the mean score of knowledge was $11.44 \pm 2.66$ and the mean score of practice was 9.67 \pm 1.70 . The calculated Karl Pearson's Correlation Value of $\mathrm{r}=$ 0.430 shows a moderate positive correlation between knowledge and practice scores

Section IV: Association of level of knowledge regarding diabetes among patients diagnosed with diabetes mellitus with their selected demographic variables.

Table 4: Association of level of knowledge regarding diabetes among patients diagnosed with diabetes mellitus with their selected demographic variables.

\begin{tabular}{|l|l|l|l|l|}
\hline Demograpic Variables & Chi square & Df & P- value & Remarks \\
\hline 1. Age in years & 5.983 & 6 & $\mathrm{p}=0.423$ & Not significant $\mathrm{P}>0.05$ \\
\hline 2. sex & 0.770 & 2 & $\mathrm{p}=0.684$ & Not significant $\mathrm{P}>0.05$ \\
\hline 3.Marital status & 1.719 & 2 & $\mathrm{p}=0.474$ & Not significant $\mathrm{P}>0.05$ \\
\hline 4.Religion & 1.729 & 4 & $\mathrm{p}=0.882$ & Not significant $\mathrm{P}>0.05$ \\
\hline 5.Educational Status & 28.382 & 4 & $\mathrm{p}=0.0001$ & Significant at $\mathrm{P}<0.001$ \\
\hline 6.Occupation & 15.905 & 8 & $\mathrm{p}=0.034$ & Significant at $\mathrm{P}<0.05$ \\
\hline 7.BMI & 0.909 & 4 & $\mathrm{p}=0.856$ & Not significant $\mathrm{P}>0.05$ \\
\hline 8.Place of residence & 9.883 & 2 & $\mathrm{p}=0.005$ & Significant at $\mathrm{P}<0.01$ \\
\hline 9. Type of Diabetes & 0.192 & 2 & $\mathrm{p}=1.000$ & Not significant $\mathrm{P}>0.05$ \\
\hline 10.Duration of Diabetes & 13.893 & 6 & $\mathrm{p}=0.028$ & Significant at $\mathrm{P}<0.05$ \\
\hline
\end{tabular}


Shelly Chabungbam et.al. Knowledge and self-care practice regarding diabetes among patient diagnosed with diabetes mellitus in selected hospitals, Kamrup (M), Assam, with a view to develop information booklet on management of diabetes: a descriptive study.

\begin{tabular}{|l|c|c|c|c|}
\hline \multicolumn{7}{|c|}{ Table 4 Continued... } \\
\hline 11.Family history of Diabetes & 0.010 & 2 & $\mathrm{p}=1.000$ & Not significant $\mathrm{P}>0.05$ \\
\hline 12. Any other illness suffering from & 9.425 & 8 & $\mathrm{p}=0.308$ & Not significant $\mathrm{P}>0.05$ \\
\hline 13. Glucometer available at Home & 2.579 & 2 & $\mathrm{p}=0.404$ & Not significant $\mathrm{P}>0.05$ \\
\hline 14. Attended session of Health education & 3.198 & 2 & $\mathrm{p}=0.202$ & Not significant $\mathrm{P}>0.05$ \\
\hline 15.Current treatment for Diabetes & 4.490 & 4 & $\mathrm{p}=0.317$ & Not significant $\mathrm{P}>0.05$ \\
\hline
\end{tabular}

Table 5: Association of level of practice regarding diabetes among patients diagnosed with diabetes mellitus with their selected demographic variables.

\begin{tabular}{|l|l|l|l|l|}
\hline Demograpic Variables & Chi square & Df & P- value & Remarks \\
\hline 1. Age in years & 4.464 & 3 & $\mathrm{p}=0.233$ & Not significant $\mathrm{P}>0.05$ \\
\hline 2. sex & 2.166 & 1 & $\mathrm{p}=0.161$ & Not significant $\mathrm{P}>0.05$ \\
\hline 3.Marital status & 0.014 & 1 & $\mathrm{p}=1.000$ & Not significant $\mathrm{P}>0.05$ \\
\hline 4.Religion & 0.013 & 2 & $\mathrm{p}=1.000$ & Not significant $\mathrm{P}>0.05$ \\
\hline 5.Educational Status & 7.807 & 2 & $\mathrm{p}=1.000$ & Not Significant $\mathrm{P}>0.05$ \\
\hline 6.Occupation & 13.81 & 4 & $\mathrm{p}=0.007$ & Significant at $\mathrm{P}<0.01$ \\
\hline 7.BMI & 1.005 & 2 & $\mathrm{p}=0.0917$ & Not significant $\mathrm{P}>0.05$ \\
\hline 8.Place of residence & 5.609 & 1 & $\mathrm{p}=0.025$ & Significant at $\mathrm{P}<0.05$ \\
\hline 9. Type of Diabetes & 1.09 & 1 & $\mathrm{p}=0.480$ & Not significant $\mathrm{P}>0.05$ \\
\hline 10.Duration of Diabetes & 19.22 & 3 & $\mathrm{p}=0.0001$ & Significant at $\mathrm{P}<0.001$ \\
\hline 11.Family history of Diabetes & 0.051 & 1 & $\mathrm{p}=1.000$ & Not significant $\mathrm{P}>0.05$ \\
\hline 12. Any other illness suffering from & 2.579 & 6 & $\mathrm{p}=0.631$ & Not significant $\mathrm{P}>0.05$ \\
\hline 13. Glucometer available at Home & 27.687 & 1 & $\mathrm{p}=0.0001$ & Not significant $\mathrm{P}>0.001$ \\
\hline 14. Attended session of Health education & 4.020 & 1 & $\mathrm{p}=0.053$ & Significant at $\mathrm{P}<0.05$ \\
\hline 15.Current treatment for Diabetes & 12.227 & 2 & $\mathrm{p}=0.002$ & Significant at $\mathrm{P}>0.01$ \\
\hline
\end{tabular}

\section{DISCUSSION}

In the present study majority, $57 \%$ belong to male and $43 \%$ of the respondents belong to female. About $92 \%$ of the respondents were married whereas only $8 \%$ are widowed. $79 \%$ of the respondent belongs to Hinduism. Majority of the respondents that is $55(55 \%)$ had secondary education. Around $23 \%$ of the respondents were self -employed.23\% of the respondent were having normal BMI. 58\% of the respondent were residing in urban area whereas $42(42 \%)$ of the respondent were residing in the rural area.

Under health related factors - 99\% had Type 2 diabetes mellitus whereas only one $(1 \%)$ of the respondent had Type 1 diabetes mellitus. About $41 \%$ of the respondent had diabetes for 6-10 years. $76 \%$ of the respondent does not have any family history of diabetes. $20 \%$ of the respondent had chronic kidney disease, majority that is $62 \%$ of the respondent had glucometer at home and $38(38 \%)$ of the respondent does not have glucometer at home. $46(46 \%)$ had taken insulin as their treatment for diabetes.

The present study reveals that out of 100 respondent $84 \%$ had moderate knowledge, $12 \%$ had inadequate knowledge and $4(4 \%)$ had adequate knowledge regarding diabetes among patients diagnosed with diabetes mellitus.
The present study is supported by the study conducted by Kaur S, Kaur H (2017) Descriptive study to assess the knowledge regarding Diabetes Mellitus among the residents of selected rural community. The result revealed that out of 100 community people $90 \%$ have average knowledge, 9\% have good knowledge and only $1 \%$ have poor knowledge. ${ }^{[3]}$

The present study is contradicted to the study conducted by Gaikar P, Kale M, Halemani S (2017) Assess the Knowledge Regarding Self-Care Management among Newly Diagnosed Type 2 Diabetic patients attending Out Patient Department at Parshuram Hospital, Ghanekhunt-Lote, Ratnagiri Dist. Maharashtra State. The study revealed that knowledge level of client 14 (46.67\%) had good knowledge, 16(53.33\%) client had average knowledge and none of them have poor knowledge ${ }^{[4]}$

The present study reveals that out of 100 respondent $52(52 \%)$ had adequate practice and $48(48 \%)$ had moderate practice regarding management of diabetes among patients diagnosed with diabetes mellitus.

The study is contradicted to the study conducted by

Karthik RC, Radhakrishnan A, Vikram A, et al, (2020), cross sectional study on Self-care practices among type II diabetics in rural area of Kancheepuram 
Shelly Chabungbam et.al. Knowledge and self-care practice regarding diabetes among patient diagnosed with diabetes mellitus in selected hospitals, Kamrup (M), Assam, with a view to develop information booklet on management of diabetes: a descriptive study.

district, Tamil Nadu. The result reveals that the overall prevalence of good self-care practices was very low $(5.6 \%)$. Moderate self-care practices were prevalent in $42 \%$ of the study participants whereas the majority $(52.4 \%)$ of the study population had poor self-care practices regarding diabetes. ${ }^{[5]}$

The study reveals that there is a moderate positive correlation between knowledge and practice scores where the value of $r=0.430$ which clearly infers that when the knowledge regarding diabetes among patients diagnosed with diabetes mellitus increases their practice level also increases

The correlation findings is supported by the study conducted by Karaoui LR, Deeb ME, Nasser L, et al (2018) on knowledge and practice of patients with diabetes mellitus in Lebanon: A multiple linear analysis showed that those with a university degree had a significantly higher knowledge (Beta $=0.448, \mathrm{p}=0.001)$ and practice score $($ Beta $=0.523 \mathrm{p}=0.047)$ than those with intermediate or primary schooling. Those study participants who reported following a special diabetes diet had a higher knowledge score (Beta = $0.482, \mathrm{p}<0.001)$ than those who did not. Knowledge score and practice score were highly correlated $($ Beta $=0.844, \mathrm{p}<0.001)$

The study reveals that the demographic variables such as educational status, place of residence, occupation and duration of diabetes had shown statistically significant association with level of knowledge. The other demographic variables had not shown statistically significant association with level of knowledge regarding diabetes among patients diagnosed with diabetes mellitus with their selected demographic variables

The study also reveals the association of level of practice regarding diabetes among patients diagnosed with diabetes mellitus with their selected demographic variables such as duration of diabetes, glucometer available at home, occupation current treatment, educational status, place of residence and attended any session of health education on diabetes mellitus had shown statistically significant association with level of practice. The other demographic variables had not shown statistically significant association with level of practice regarding diabetes among patients diagnosed with diabetes mellitus with their selected demographic variables

\section{CONCLUSION}

From the present study it was concluded that majority of the patient had moderate knowledge and majority of the patient had adequate practice. Although many participants have knowledge regarding management of diabetes mellitus, there are still who are unaware about the other domains of self- care practices which are equally important for a diabetic patient in maintaining a healthy lifestyle. So, proper awareness regarding self- care management of diabetes is needed in order to improve the knowledge and domains of self - care practices among diabetic patient which will help to prevent from diabetic related complications.

\section{Acknowledgement: None}

\section{Conflict of Interest: None}

\section{Source of Funding: None}

Ethical Approval: Approved

\section{REFERENCES}

1. [Internet]. Who.int. 2021 [cited 12 August 2021]. Available from: https://www.who.int/diabetes/publications/ Definition\%20and\%20diagnosis\%20of\%20 diabetes_new.pdf

2. Dinesh PV, Kulkarni AG, Gangadhar NK. Knowledge and self-care practices regarding diabetes among patients with Type 2 diabetes in Rural Sullia, Karnataka: A community-based, cross-sectional study. Journal of family medicine and primary care. 2016 Oct;5(4):847

3. Kaur S, Kaur H. A Descriptive Study to Assess the Knowledge Regarding Diabetes 
Shelly Chabungbam et.al. Knowledge and self-care practice regarding diabetes among patient diagnosed with diabetes mellitus in selected hospitals, Kamrup (M), Assam, with a view to develop information booklet on management of diabetes: a descriptive study.

Mellitus among the Residents of Selected Rural Community, Gurdaspur, Punjab. International Journal of Nursing Education and Research. 2017;5(1):19-26.

4. Gaikar MP, Kale MM, Halemani MS. Assess the Knowledge Regarding Self-Care Management among Newly Diagnosed Type 2 Diabetic Clients Attended Out Patient Department at Parshuram Hospital, Ghanekhunt-Lote, Ratnagiri Dist. Maharashtra State. JMSCR. 2017

5. Karthik RC, Radhakrishnan A, Vikram A, et al. Self-care practices among type II diabetics in rural area of Kancheepuram district, Tamil Nadu. Journal of Family Medicine and Primary Care. 2020 Jun;9(6):2912.
6. Karaoui LR, Deeb ME, Nasser L, et al. Knowledge and practice of patients with diabetes mellitus in Lebanon: a crosssectional study. BMC Public Health. 2018 Apr 20;18(1):525. doi: 10.1186/s12889018-5416-7.

How to cite this article: Chabungbam S, Bayan $\mathrm{S}$. Knowledge and self-care practice regarding diabetes among patient diagnosed with diabetes mellitus in selected hospitals, Kamrup (M), Assam, with a view to develop information booklet on management of diabetes: a descriptive study. Int J Health Sci Res. 2021; 11(9): 150-156. DOI: https://doi.org/10.52403/ ijhsr.20210923 